\title{
ZALAMEA: APROXIMACIÓN HISTÓRICA DEL TOPÓNIMO. Censo de tropas concejiles en el reinado de Felipe II http://dx.doi.org/10.33776/hh.v15i0.5282
}

Antonio VÁzQuez León*

Fecha de recepción: 13/09/2019

Fecha de aceptación: 27/11/2019

\section{Resumen}

El presente estudio aborda el origen y posterior evolución del topónimo "Çalamea", que curiosamente hoy escribimos como Zalamea, pues con la evolución de la lengua romance castellana la ç se acabó sustituyendo por la letra z en el siglo XVIII. Sólo dos poblaciones situadas en el sudoeste español recogen esta nombradía: en tierras pacenses (Zalamea de la Serena) y en tierras onubenses (Zalamea la Real). Este vocablo se registra por primera vez en 1270 , y se vuelve a documentar con motivo de la conquista de las tierras andaluzas. Este término ha sido estudiado en diferentes épocas y con visiones muy distintas, romántica, decimonónica, etc.

Si el topónimo de "Çalamea" venía navegando desde tiempos remotos, emergiendo en tierras andaluzas en 1279, todavía habría de pasar alrededor de 500 ańos para su definitiva configuración. La "Çalamea" onubense vivió un momento de convulsión en el año 1569, cuando se realizó el "padrón de los hombres aptos para ir a la guerra" con motivo del levantamiento morisco que había tenido lugar en Órgiva (Granada). El Cabildo de la Catedral había nombrado a Luis de Lezana alcalde mayor de Zalamea. Con tal motivo, en enero de ese mismo año se desplazó a la localidad para realizar un padrón de todos los hombres de la villa y de sus aldeas. De todos ellos, aproximadamente un $68 \%$ de los hombres provenían de las aldeas y el resto de la villa.

\section{Palabras clave}

Toponimia; linguística; dialectología; etnografía, historia local; historia social.

\section{Abstract}

The present study addresses the origin and subsequent evolution of the place name "Çalamea”, which we curiously write today as Zalamea, because with the evolution of the Castilian Romance language, ç was eventually replaced by the letter $\mathrm{z}$ in the 18 th century. Only two populations located in the southwest of Spain collect this name: in pacenses lands (Zalamea de la Serena) and in Huelva (Zalamea la Real). This word is registered for the first time in 1270, and is documented again on the occasion of the conquest of the Andalusian lands. This term has been studied at different times and with very different visions, romantic, nineteenth, etc.

If the name of "Çalamea" had been sailing since ancient times, emerging in Andalusian lands in 1279, it would still be around 500 years for its final configuration. The "Çalamea" onubense lived a moment of convulsion in the year 1569 , when the "standard of men fit to go to war" was carried out on the occasion of the Moorish uprising that had taken place in Órgiva (Granada). The Cabildo de la Catedral had appointed Luis de Lezana, mayor of Zalamea. For this reason, in January of that same year he moved to the town to carry out a list of all the men in the town and their villages. Of all of them, approximately $68 \%$ of the men came from the villages and the rest of the village.

\section{KeY WORDS}

Toponymy; linsguistics; dialectology; etnography; local history; social history

* Antonio Vázquez León (†Huelva, 2020) estudió en el Colegio Universitario de La Rábida, formando parte de su primera promoción, y se licenció y doctoró en Historia en la Universidad de Sevilla con una tesis sobre Las Ermitas Rurales de la provincia de Huelva (Huelva, Diputación Provincial, 1997). Dedicó su carrera a la docencia y la investigación de la historia en la ciudad de Huelva. Huelva en su Historia quiere contribuir a la perpetuación de su memoria. 


\section{AproximaCión Histórica AL TOPÓNIMO DE "ZALAMEA"}

Cada vez que lo pienso, cada vez se asemeja más la vida de los hombres y la de las palabras; son vidas paralelas; nacen, evolucionan, mueren. De igual modo, su destino no es otro que el olvido de los tiempos. ¿Qué sería del hombre sin las palabras? Estaríamos sometidos a una primariedad biológica; sin expresión, sin individualidad. Con la palabra, el hombre ha podido identificarse a sí mismo, construyendo un mundo nuevo, más transcendente, más espiritual. Hemos construido sonido a sonido, palabra a palabra, eso que los viejos filósofos llamaban "El alma".

\section{LA FUERZA DEL HABLA POPULAR}

El presente artículo trata de aproximarnos al origen y posterior desarrollo histórico del topónimo Zalamea, que no se repite en el marco territorial peninsular salvo en dos poblaciones del suroeste espańol: en la localidad pacense de Zalamea de la Serena y en la localidad onubense de Zalamea la Real. La mayoría de los nombres de municipios tienen un origen anterior; muchos nombres de lugar de origen árabe, latino o anterior (celta, íbero, etc.), fueron adaptados gráficamente pero no traducidos ni sustituidos. Eso nos muestra la tendencia conservadora de la toponimia. Un ejemplo de lo que venimos manifestando lo observamos en el topónimo de la capital onubense; la transcripción que diversos autores árabes realizan del término latino Ónoba, Ónba, Olba o Velba, como se le nombraba en época romana, evolucionó y pasó a denominarse Awnaba, Waniba, Walba, y más tarde en época cristiana Huelua, Huelva.

Hay topónimos que sencillamente son identitarios, no tienen contenido, sólo nombran; hay muchos otros con contenido semántico que pueden designar cualidades geográficas, como el relieve; hidrónimos que describen fuentes y ríos; topónimos que nos hablan de la flora y la fauna. Otros nos hablan de la geografía humana, un lugar para vivir, cultivar, comerciar, defenderse (castillos y torres) o rezar. Muchos otros derivan de personas.

La lengua, para que pueda seguir funcionando como tal, para que pueda satisfacer las nuevas necesidades que la sociedad plantea, debe cambiar y se ve sometida a fuerzas diversas, de no ser así se produciría un rompimiento en las relaciones sociolingüísticas. La analogía es considerada por muchos lingüistas la causa más poderosa de la evolución, pero también es otra, la ley del menor esfuerzo o ley de la economía fisiológica que incide mucho en el cambio y posterior transformación de las palabras. Esta característica, que es muy propia de las expresiones del habla popular, modifica sustancialmente los topónimos y nos ayuda a comprender mejor cuál ha sido su evolución. De ahí que detalle con precisión algunos ejemplos de la toponimia del término de Zalamea la Real, para demostrar con más evidencia lo que vengo manifestando.

La aldea de Marigenta ${ }^{1}$ empezó su construcción inmediatamente después de la repoblación cristiana, edificando las típicas chozas de pastores hasta la concentración de éstas

1 Al topónimo Marigenta en los siglos XVI, XVII y XVIII se le complementaba con la calificación de "Monte" o "Majada". 
y, por tanto, la fundación del poblado 2 . Su denominación responde al nombre de María Vicenta. Este matronímico se refiere al primer colono o uno de los primeros fundadores del lugar, de tal manera que cuando alguien de Zalamea preguntaba dónde vas, la respuesta era evidente: voy a ver a María Vicenta. Con el transcurso del tiempo el nombre empieza a deformarse porque hay una regla no escrita en el lenguaje popular que viene a decir que las palabras cuanto más breves, más sonoras y audibles, mejor proyección tienen. Así, en el S. XVI la aldea se registra en los documentos como Marijenta, Marixenta; los dos sustantivos se habían unificado perdiendo fonemas y la c se convierte en $\mathrm{j}$ o x. Los escribanos del S.XV escribían "Vizente, Vixente, Vicente, Viçente", no había norma, de ahí que Vicenta quedara en "xenta". A partir del siglo, la x se sustituye por j, esta característica es habitual en todo el reino de Espańa; por último, la c se sustituye por el fonema g. Por tanto, afirmamos, siempre de manera general, que en el siglo XVIII la nombradía de la aldea queda definitivamente establecida.

Hay palabras, como los nombres propios, que su función no es la de significar, no es la de querer decir, sino la de designar, la de identificar; de ahí este matronímico, "Marigenta"; no lo podemos entender como que alberga contenido, que tiene significado, se debe entender exclusivamente en relación a lo que designa.

La aldea de Las Delgadas se fundó inmediatamente después de la repoblación de Zalamea; pastores labriegos deseosos de encontrar buenas tierras, abundantes aguas y buenos pastos edificaron en ese lugar "algunos tugurios o chozas ...... de los que dos mujeres hermanas, llamadas Delgadas por serlo de apellido ......se vinieron aquí a hacer sus tenencias y viviendas, y se les fueron agregando vecinos..."”. Este informe lo realizó el cura de Las Delgadas el 22 de agosto de 1786. A mediados del siglo XVI, en un documento escrito relativo a los hombres aptos para ir a la guerra, el nombre de la aldea, sólo y exclusivamente es Delgadas ${ }^{4}$. No sabemos con precisión si la información del cura es correcta; con posterioridad al S. XVI los documentos la rubrican como Las Delgadas. Esta última nombradía parece que es más propia de la evolución que sufren los topónimos cuando la gente del lugar perfila la palabra a través del sonido, sin soporte escrito, sin reglas, sólo por la fuerza de la expresión popular. Sabemos que la forma final de un topónimo es consecuencia, por tanto, de su motivación inicial, de su origen, pero también de un proceso posterior de evolución, de transformación, y esa nueva designación es al fin y al cabo lo que más importa.

Se pueden llegar a situaciones ciertamente curiosas; la aldea del Monte de Alonso Romero es un lugar muy cerca de Las Delgadas y perteneciente al término de Zalamea la Real, que toma el nombre del inquilino dueño de ese "Monte". En el siglo XVII los documentos así lo reflejan; sin embargo, poco tiempo después el nombre experimenta un cambio designándose a la aldea como Monte Sorromero, incluso hubo un intervalo de tiempo donde ambas denominaciones eran usadas indistintamente. Posteriormente, el

2 A. Vázquez León, “ Marixenta, Marijenta, Marigenta, Majada de Marigenta, Monte de Marigenta”, Revista de Feria. Vol. I no 5. Ayuntamiento de Zalamea la Real (1983).

3 J.E. Ruíz González, Los pueblos de Huelva en el siglo XVIII, Huelva, 1999, p. 131.

4 Sevilla, Archivo de la Catedral de Sevilla. Caja 11089, nº 2. 
uso se generalizó en favor de esta última denominación reflejándose así en los documentos del siglo XVIII. Como podemos comprobar en este caso, para determinar con claridad el origen y significado de un topónimo, la existencia de documentos que certifiquen el origen y su posterior evolución son claves para el rigor histórico. Sin embargo, la falta de documentos provoca que las conclusiones puedan ser aventuradas 5 .

Rodrigo Amador de los Ríos, abogado, arqueólogo e historiador, realiza un estudio amplio de un gran número de poblaciones de la provincia de Huelva para la serie España: Sus monumentos y artes, su naturaleza e historia, publicado en 1891 en Barcelona. Con una visión decimonónica del acontecer histórico, analiza el topónimo de un antiguo lugar denominado "Abejú", y nos dice "que el nombre primitivo árabigo fue el AbenHud, haciendo referencia ya al famoso Seíf-ud-Dolah de los días de Alfonso VII, ya al no menos célebre Aben-Hud del siglo XIII".

Prosigue Amador de los Ríos manifestando que "los moradores de allí tienen tradición que las gentes que el rey Salomón enviaban por oro y plata a aquella tierra, le edificaron y le llamaron del nombre de Salomón, Salamea”, de ahí que el nombre acabase en la actual Zalamea. A finales del siglo XIX, este insigne personaje, Rodrigo Amador de los Ríos, al estudiar el término y tropezarse con este topónimo facilitó unas conclusiones más propias del mundo literario que del rigor histórico, por otra parte lógico dentro del contexto cultural de aquella época ${ }^{7}$.

En 1785, el informe que realizó el cura de Zalamea a Don Tomás López, geógrafo de su majestad, le relacionaba numerosas aldeas que ya habían desaparecido, entre ellas Aviud $^{8}$. Esta aldea se abandonó con motivo de la peste que se dio en la segunda mitad del siglo XVIII. Con el correr de los tiempos, los lugareños fueron transformando el topónimo y derivó en Abejú. En realidad, Aviud es un nombre de raíz hebrea y el primer morador o uno de los primeros moradores que fundaron este lugar. Una aldea más con nombre de su fundador.

Para enfatizar más los cambios que produce la dicción popular daré un ejemplo de topónimo hagiográfico, que es donde adquiere una dimensión más clara todo lo que venimos exponiendo. En la provincia de Huelva Santa Eulalia ha contado con una gran devoción, principalmente en las poblaciones de Santa Olalla del Cala o Almonaster la Real. Curiosamente, con la conquista cristiana la devoción toma cuerpo en nuestra provincia; así, la ermita de Santa Eulalia, construida en las afueras del pueblo, dio nombre a la actual población de Santa Olalla del Cala. La devoción a la Santa que hay en Almonaster la Real motivó que en una dehesa cerca de la confluencia del barranco Zancolín con la rivera de su mismo nombre, se edificara la ermita a la Santa. En su capilla mayor se conserva una serie de pinturas, tanto en las paredes del presbiterio, como en la bóveda. Debajo

5 Esta aldea está prácticamente desaparecida; la compra de alguna de sus casas por personas residentes en Sevilla mantiene la sensación de estar habitada.

6 R. Amador de los Ríos, España: sus monumentos y artes, su naturaleza e historia. Volumen de Huelva. Barcelona, 1891. Reedición 1983, pp. 581.

7 R. Amador de los Ríos, España: sus monumentos y artes, su naturaleza e historia, Volumen de Huelva. Barcelona, 1891. Reedición 1983, p. 581.

8 J. E-Ruíz González, Los pueblos de Huelva en el siglo XVIII, Huelva, 1999, p. 323.

Huelva en Su Historia - $3^{\text {a ÉPOCA • Vol. I } ~ • ~} 2021$ • [53-67] • ISSN 1136-6877 @ Universidad de Huelva 
de la ventana podemos leer una cartela que dice: "Esta ermita fue construida al servicio de Dios y de la Buenaventurada Santa Olalla y reverencia del bienaventurado Señor San Sebastian y el Señor Santiago haecomniapictavitur" ". Las pinturas han sido catalogadas a finales del S. XV, si bien algunos historiadores creen que son un poco más tardías.

Sabemos que la devoción a la imagen se fue asentando en la provincia a través de los nuevos repobladores que bajaban de Extremadura; ellos traían el nombre y ellos lo modificaron; fue un proceso lento, donde el sustantivo Eulalia se convirtió en Olalla; de ahí que expongamos este caso para demostrar la fuerza del decir popular y por ende lo cuidadosos que debemos andar en estas investigaciones. Así, a partir de su creación, un topónimo puede evolucionar, puede perder transparencia o perder por completo la evidencia de la conexión con su origen y motivación.

La toponimia es una ciencia que, aun formando parte de la lingüística, auxilia con sus conclusiones a otros campos del conocimiento. De gran importancia es la relación que se establece entre el hombre y el suelo porque la toponimia juega un papel crucial. Pero quizás sea en su relación con la historia el aspecto que más haya interesado a los estudiosos. Así pues, observamos como la toponimia puede auxiliar a la arqueología, a la geografía humana o a la ecología, y de igual modo ella puede valerse de estas ciencias para explicarse en parte a sí misma.

\section{Los primeros hallazgos documentados del topónimo "Zalamea" (Zalamea de la Serena)}

Centrándonos en el estudio de las poblaciones de Huelva y Badajoz, recordemos que eran tiempos muy difíciles para aquellas gentes del siglo XIII, porque aquellos cristianos y musulmanes no encontraban más paz que imponer por la fuerza su modelo de vida. En aquella Andalucía de época bajo medieval los reinos taifas musulmanes se veían muy amenazados por la maquinaria de guerra cristiana que habían logrado romper la frontera natural del Tajo y que ahora amenazaban con conquistar el corazón más íntimo de Al-Ándalus. Cuando aquellos cristianos llegaron a la Penillanura de la Serena, que no es otra cosa que la colmatación de un antiguo lago del Plioceno, cuya altura media está entre 400 y 500 metros y con sierras que pasan de los 800 metros de altitud, estaban posicionándose en el reborde norte de Sierra Morena, donde el territorio alberga un suelo poco profundo, no alcanzando en la mayoría de los casos los 60 centímetros, y la pizarra se enseñorea conformando unas formaciones que en Extremadura se conocen como "dientes de perro" 10 .

Pronto alcanzaron un antiguo poblado romano, conocido como "Municipium Flavium Iulipense", situado en una de las redes de comunicación más importante de la zona, que conectaba Córdoba con este asentamiento. No se ponen de acuerdo los historiadores de si fue en 1232 o 1234 cuando fue conquistado a los árabes este lugar, por eso tampoco se sabe si fue el quinto Maestre de la Orden de Alcántara, Arias Pérez ${ }^{11}$, o el sexto Maes-

9 A. Vázquez León, Ermitas rurales de la provincia de Huelva, Huelva, 1997, p. 64.

10 A. Bernal Estévez, Poblamiento, transformación y organización social del espacio extremeño, Cáceres, 1998

11 A.M. Castaño Fernández, Los nombres de la Serena. Mérida, 1998, p. 73. 
tre de esta orden, Pedro Maestre ${ }^{12}$, quien puso fin a la dominación árabe arrebatándoles el castillo de Medellín y otras fortalezas y villas de la comarca.

En 1240, las órdenes de Santiago y Alcántara, que intervinieron decididamente en la conquista de gran parte del término de la actual provincia de Badajoz, delimitaron sus posesiones. Las tierras de la comarca de la Serena pasaron a pertenecer a los caballeros de Alcántara, Orden que tuvo sus inicios en tierras portuguesas.

Sabemos que en 1241 Fernando III donó Benquerencia a la Orden de Alcántara. En este documento se señalan los términos de Benquerencia y Magacela; no hay alusión alguna a Zalamea de la Serena, como tampoco cuando un año antes, en 1240, la Orden de Alcántara y la de Santiago firmaron un acuerdo de límites territoriales para la zona de La Serena. En el acuerdo de ambas órdenes en ningún momento se recoge la nombradía de Zalamea, ni tampoco la de un comendador que nos hiciera pensar de la existencia de la población, como sí ocurre con Magacela y Benquerencia ${ }^{13}$. Estas circunstancias nos obligan a considerar que Zalamea en aquellos primeros momentos se podía desarrollar como una entidad pequeńa o un hábitat de forma dispersa.

Por todo lo manifestado, inferimos que los centros rectores de La Serena durante el final del periodo islámico habrían sido Magacela y Benquerencia, los cuales conservaron una parte sustanciosa de su territorio de cara a la nueva organización jurisdiccional. Zalamea debió formar parte como asentamiento dependiente de alguno de ellos. Desde luego, basándonos en fuentes documentales no podemos confirmar su origen musulmán porque no se registra en los mismos, ni tampoco en los primeros momentos de la conquista cristiana es recogido el topónimo Zalamea, dato de importancia para determinar su origen.

Es evidente que un territorio realmente no es ocupado si no hay una población que se asiente en ese espacio; las tierras de Zalamea, a raíz de su conquista y por encontrarse limítrofes a los terrenos o posesiones de la Orden de Santiago, estuvieron sometidas a disputas territoriales, por lo que surgió la necesidad de elaborar un nuevo deslinde entre los caballeros de Alcántara y Santiago en el año de 1254. Como consecuencia de estas tensiones, la orden de Alcántara se interesó por mantener una ocupación más efectiva del territorio y evitar la apropiación indebida por parte de los habitantes de los concejos santiaguistas. Así, desde los primeros momentos de la conquista cristiana se debió pasar de un hábitat muy reducido a una ocupación más efectiva y, de este modo, defender las nuevas tierras asignadas a la Orden de Alcántara.

"En suma, al igual que ocurrió en otros espacios extremeños, se procuró el establecimiento de asentamientos en los extremos de los términos concejiles o jurisdiccionales para evitar la usurpación de tierras por pobladores ajenos. Por ello, la Institución Alcantarina fomentó la ocupación efectiva de Zalamea y le otorgó después una carta de población en 1270. La carta alude a "los que moran en Zalamea"; lo que nos confirma que no se trataba de un lugar de nueva creación en el momento de la concesión del documento.

12 A.M. Castaño Fernández, Los nombres de la Serena. Mérida, 1998, p. 73.

13 L.V. Clemente Quijada, "Agricultura, sociedad y poder en Zalamea de la Serena (Siglos XV-XVI)", Revista de Estudios Extremeños, Tomo LXVIII, No II (2012), p. 660. 
La medida buscaba consolidar la presencia permanente de hombres sobre un territorio muy alejado de las dos fortalezas rectoras y, por tanto, difícilmente controlable frente a los santiaguistas si no se instalaban pobladores sobre él. Estimamos que es entonces cuando Zalamea se escinde de Magacela o Benquerencia y pasa a tener estatus de villa y término propio" ${ }^{14}$.

El origen del nombre de Zalamea ha sido estudiado por diferentes autores y en épocas muy distintas. Francisco Barrantes Maldonado, juez eclesiástico de la villa de Zalamea de la Serena en el siglo XVII, manifestaba que el nombre era propiamente arábigo, en cuya lengua "cala" venía a significar lugar fortificado ${ }^{15}$. Es evidente que hay poblaciones cuyo topónimo empieza por esta raíz, pero no sucede lo mismo en tierras extremeñas porque no hay ninguna población que empiece por esta base. Sin embargo, sólo encontramos el radical "cala" en la población pacense de Calamonte, pero no como lugar fortificado sino referido a un lugar, un monte, una sierra, lugar elevado cuya etimología se adscribe a la raíz celta cala. En los topónimos menores encontramos con frecuencia este lexema celta; así, en Baños de Montemayor, testimoniamos en su orografía la sierra de Calamocha; en Zarza de Granadilla, Los Calamas, etc.

Todas estas adscripciones, todo este pensamiento de provenir la palabra de la lengua árabe ha tenido diferentes interpretaciones: para Miguel Asín Palacios se trata de un nombre árabe, cuya raíz no viene a significar fortaleza o lugar fortificado, sino que "significa saludable, relacionándose, pues con la raíz salam “la paz”, y aludiendo, sin duda, a la buena disposición del lugar y su fertilidad"16.

Otra versión diferente la aporta Alonso de Torres y Tapia, el cual señala que en el dístilo de Zalamea, monumento conmemorativo funerario fechado en el año 102 d.C., había una inscripción donde se leía "Haec est coela mea" que venía a significar "esta es mi celda" y de ahí vendría el topónimo de Zalamea (coela mea) ${ }^{17}$. El autor de la Crónica de la Orden de Alcántara nació en Villanueva de la Serena el año de 1578. Fue rector del Colegio de la Orden en Salamanca y Prior del convento de Alcántara. Un erudito de la época, un documentalista, muy conocedor de este mundo, con buenas fuentes de información, pero un hombre de su tiempo, lo que nos obliga a estudiarlo con mucho cuidado.

Este monumento funerario contaba con once siglos de existencia en el momento de la conquista de estas tierras, su belleza atraía la mirada de todo el que pasara por el lugar. No hay llamada de atención más explícita ni cartel más publicitario para contar las aventuras o desventuras de los romanos de aquel entonces.

Cuando se refiere al dístilo de Zalamea y el cambio de nombre que sufre la población romana Iulipa, argumenta nuestro cronista que sucedió o bien para lisonjear al emperador Trajano o bien porque los "moros" perdieron o quisieron que se perdiera la

14 L.V. Clemente Quijada, "Agricultura, sociedad y poder en Zalamea de la Serena (Siglos XV-XVI)", Revista de Estudios Extremeños, 2012, Tomo LXVIII, No II (2012), p. 662.

15 A.M. Castańo Fernández, Los nombres de la Serena. Mérida, 1998, p. 73.

16 A.M. Castaño Fernández, Los nombres de la Serena, Mérida, 1998, p. 73.

17 A. Torres y Tapia, Crónica de la Orden de Alcántara, Tomo Primero, Madrid, 1763. 
nombradía de las ciudades y villas, dándoles nombre con lo más notable que hubiese en ese lugar y que en este supuesto no era otra cosa que el cenotafio referido y la inscripción que había en la urna, y para argumentarlo el Prior alcantarino refiere un ejemplo parigual, de cómo la población de Lancia cambió su nombradía con los musulmanes en el siglo XII por la de Alcántara (Al-Qantarat «El Puente») ${ }^{18}$. En su libro "Crónicas de la Orden de Alcantara” Alonso de Torres y Tapia especula de dónde y cómo pudo surgir la palabra, pero la falta de claridad al decir después que pudo ser empleada y corrompida por los "moros" ha dado lugar a una controversia de si el término era latino o procedía del árabe. Necesitamos de una contextualización histórica para ayudarnos a aclarar en parte el problema.

No hay registro de este topónimo en documentos árabes de la época, ni tampoco aparece escrito el término en los primeros momentos de la conquista de la comarca de la Serena; a partir de la conquista de Magacela y Benquerencia, pero unas décadas después, es cuando se registra por primera vez en las fuentes cristianas. Es éste un dato muy importante, como también lo es que no hay evidencia arqueológica que confirme una población estable y permanente en Zalamea de la Serena durante el periodo musulmán; no negamos que estuviera poblado, pero desde una perspectiva de un sitio, de un lugar sin relevancia, como tantos otros, o que se tratara más bien de un hábitat disperso.

\section{Nombradía y desarrollo del topónimo de Zalamea la Real}

Conocemos por el privilegio rodado de Alfonso X fechado el 16 de diciembre de 1279 y confirmado por otro posterior de 11 de enero de 1280 , que las poblaciones de Almonaster la Real y Zalamea la Real en la provincia de Huelva se permutan por Cazalla de la Sierra (Sevilla), pasando a pertenecer las primeras al Arzobispado de Sevilla y la segunda a la orden de Calatrava ${ }^{19}$. Cuando estudiamos el documento observamos que la palabra Zalamea se escribe como Çalamea, de igual manera que en la Carta poblacional de 1270 de Zalamea de la Serena. No hay testimonios que recojan esta denominación ni en fuentes documentales árabes de la provincia de Badajoz ni en las del reino taifa de Niebla. Es con la llegada de los repobladores cristianos cuando el término se hace presente, adquiriendo a continuación una cantidad de variantes propiciadas por el decir popular, la transmisión oral y la falta de una estructuración gramatical, características propias de la lengua romance.

No podemos olvidar que el término de Zalamea se desarrolla en un proceso histórico de conquista. Es un término que se expande a través de los colonos cristianos y que vuelve a surgir a menos de 200 Kilómetros de su nacimiento, en la provincia de Huelva, siguiendo las rutas de bajada hacia el sur, en el mismo camino repoblador que trazaron los cristianos en el siglo XIII. Desde 1232 o 1234, con la caída de la comarca de la Serena, tan solo tuvieron que transcurrir 17 años para que el reino taifa de Niebla, gobernado por Aben Mafof, se conquistase y pasase a formar parte del reino de Alfonso $\mathrm{X}$ el Sabio. De su extenso término las tierras pertenecientes a Zalamea la Real, práctica-

18 A. Torres y Tapia, Crónica de la Orden de Alcántara, Tomo Primero, Madrid, 1763, p. 268-271. 19 Sevilla, A.C.S. Sec. IX, Fondo Histórico General, cap. 4, doc. 7 
mente la cuenca minera de Riotinto, quedaba liberada para la llegada de los repobladores a este nuevo lugar. No fue hasta diciembre de 1279 , cuando por un privilegio rodado del monarca Alfonso X, documento anteriormente señalado, sabemos que Almonaster la Real es definida como villa con castillo; sin embargo, Zalamea la Real era considerada simplemente como un lugar.

Desconocemos qué circunstancia provocó la repetición del nombre, no hay base documental para apoyarnos, pero por otra parte es habitual en el territorio nacional español encontrarnos con decenas de coincidencias semánticas y etimológicas como sucede entre nombres de municipios aragoneses y valencianos ${ }^{20}$, que han copiado literalmente el topónimo, como es nuestro caso, o bien presentan ligeras diferencias gráficas. Participar de una historia común y de una geografía compartida propicia estas coincidencias toponímicas. Atravesada la comarca de la Serena por las estribaciones de Sierra Morena como también dos tercios de la actual provincia de Huelva, en general es un terreno para la agricultura y la ganadería, pero también de minas. En la orografía de Zalamea de la Serena encontramos pequeńas explotaciones mineras que incluso algunas se remontan a época tartésica. Qué pensarían aquellos colonos cuando llegaron a tierras andaluzas y visionaron aquellas minas conocidas como del rey Salomón y, a su vez, la explotación minera más importante de toda la cuenca del mediterráneo.

Si bien en la carta puebla fundacional de Zalamea de la Serena como en el privilegio rodado de Alfonso X la grafía del topónimo es Çalamea, es a través de un documento de principios del siglo XV donde podemos apreciar la evolución del término; nos estamos refiriendo a las reglas de San Vicente Mártir ${ }^{21}$, patrón de Zalamea la Real, elegido como Santo protector el año de 1425, tan sólo 145 años después de la conquista de este lugar. El escribano de aquel entonces rubricó el nombre bajo grafías diferentes, siguiendo el orden de esa relación escribió: Çalama, Zalama, Çalamea, Zalamea, y lo sabemos por una copia original que se hizo en 1638 por encontrarse el documento original, en aquellos años, en mal estado. Entre estos toponímicos nos llama la atención Çalama; es curioso que el topónimo Calama con c normal también lo encontramos en tierras extremeñas, como también se testimonia en otra población del continente americano; se trata de una ciudad, Calama, ubicada al norte de Chile, donde hay minas de cobre muy similares a las de Zalamea la Real. En este país sudamericano no hay una explicación lógica del origen del nombre, algunos lo atribuyen a terminología indígena, pero lo más lógico es pensar que la palabra saltó "el charco" y se llevó a América al igual que muchos otros nombres de ciudades y pueblos que se vieron rebautizados en el nuevo continente. Podemos decir que desde su conquista la forma más habitual de nombrar a estas poblaciones, extremeña y andaluza, fue Çalamea y esto prácticamente perduró hasta el siglo XVI. Este vocablo

20 J.C. Membrado Tena, Etimología y semántica de topónimos municipales valencianos y aragoneses Departamento de Geografía, Universidad de Valencia, Actes d'OnomásticaVII Jornada Xérica 2013, 2014, https://www.academia.edu/6677892/ETIMOLOG\%C3\%8DA_Y_SEM\%C3\%81NTICA_DE_ TOP\%C3\%93NIMOS_MUNICIPALES_VALENCIANOS_Y_ARAGONESES

21 A. Vázquez León, Ermitas rurales de la provincia de Huelva, Huelva, 1997, p. 377. 
quedó fijado a partir del siglo XVIII y hasta el momento presente en ambas poblaciones como Zalamea.

En definitiva, no hemos podido encontrar un dato preciso que nos ayude a sacar conclusiones irrebatibles. La etimología árabe la dan por correcta todos los autores basándose en la autoridad de Asín Palacios (uno de nuestros mejores arabistas), como lo hizo García y Bellido en el "Dystilo de Zalamea." y lo hace E. Nieto Ballester en su Diccionario de Topónimos. Sin embargo, la falta de registros documentales de este topónimo, unido a otros datos relevantes que refuercen el contexto histórico, no nos permiten dar por concluido este estudio.

De lo manifestado por Alonso de Torres y Tapia relativo a la inscripción labrada en el díptico de Zalamea de la Serena "Haec est coela mea", sabemos que Coela y Coelia son nombres propios femeninos: el primero indígena pre-romano y el segundo latino. Pero no existe en latín el apelativo coela, y tampoco se ha encontrado el epígrafe; de modo que la inscripción ya fue clasificada por Hübner como falsa en el CIL II. Se razona su falsedad explicando que Torres y Tapia ha forzado ese sintagma cambiando cella por coela para explicar la etimología de Zalamea.

Partiendo de la hipótesis de Coela mea, habría que tratar de "restituir" cómo pronunciarían eso los musulmanes y cómo lo adaptaron los cristianos. Pensar en una evolución directa desde Roma al romance en un territorio ocupado durante 500 años por otro pueblo de lengua totalmente distinta es impensable. Por otra parte Coela hubiera devenido "Cela" en castellano y mea "mía"; es decir, se podría hipotetizar "Celamía", de donde no se explicaría el cambio o evolución a Zalamea ${ }^{22}$. Habrá que esperar hallazgos más fiables para poder descifrar definitivamente el origen de este topónimo.

Podemos concluir que, al igual que ocurre con la gran mayoría de los topónimos reintroducidos en otros lugares del territorio español, la nombradía del pueblo de Zalamea la Real proviene de las tierras pacenses; es uno más de tantos nombres que los repobladores traían en las alforjas a las nuevas tierras colonizadas. Al mismo tiempo, hemos podido seguir la evolución de este topónimo a raíz de la conquista cristiana en el contexto de la lengua romance castellana (Çalama, Zalama, Çalamea, Zalamea).

\section{Los tercios concejiles de Zalamea la Real}

Con la conquista del Reino de Granada se firmó la última capitulación el 25 de noviembre de 1491. Las condiciones que se establecieron a los vencidos aún venían presididas por la mentalidad de la vieja idea medieval de que hay que convivir con el enemigo; por tanto, se respetarían las costumbres, sus leyes y su religión. Sin embargo, pronto se empezaron a imponer medidas contrarias a la población morisca. El desencuentro poco a poco se fue imponiendo, hasta llegar el momento de la expulsión que tuvo lugar entre 1609 y 1614 por orden de Felipe III. El acontecimiento fue como una gran catástrofe natural donde nada es previsible y todo queda arrasado sin vuelta atrás.

22 “Agradezco las sugerencias sobre la tradición epigráfica y etimológica de Zalamea, que me hizo José Luis Ramírez Sádaba, en su condición de colaborador para la reedición del CIL II”. 
En aquellos primeros momentos, fue el conde de Tendilla quien recibió muchas tierras y vasallos tras la conquista de Granada y fue el arzobispo de Granada, Hernando de Talavera, quien puso en marcha la conversión de los mudéjares con una política de respeto, con tal voluntad que incluso aprobaba la utilización de la lengua árabe como lengua litúrgica. Pero no era aquel tiempo para la reflexión ni el acuerdo; ambas partes se enrocaban sin dar pasos adelante y al final, el que más poder tenía implantaba su voluntad. De inmediato se aplicaron medidas contrarias a lo pactado, como la prohibición de llevar armas o la de comprar tierras, etc. Según Julio Caro Baroja, la razón fundamental de éstas fue la necesidad de asegurar que Granada no sirviera de base para futuros ataques e invasiones procedentes del norte de África ${ }^{23}$.

Con la llegada del cardenal Cisneros a Granada en 1499 la situación cambió, al no tener más alternativa los mudéjares que convertirse al cristianismo o ingresar en prisión. Hubo intento por parte del conde de Tendilla y el arzobispo Hernando de Talavera de volver a la situación anterior, pero el cardenal Cisneros apoyaba la idea de que los mudéjares debían ser convertidos o esclavizados. Con el paso del tiempo la situación se fue recrudeciendo. Los reyes mantenían una política más moderada pues consideraban que si no se convertían al cristianismo, lo harían sus descendientes.

El 12 de febrero de 1502, los Reyes Católicos promulgaron una real cédula por la que se obligaba a todos los mudéjares del reino de Castilla a elegir entre el cristianismo o el destierro. La inmensa mayoría optó por la conversión y a partir de esa fecha los mudéjares castellanos pasaron a ser llamados moriscos. ${ }^{24}$

Sin embargo, la campańa evangelizadora no daba resultados y el rey nombró una junta para que propusiera medidas para acabar con esa situación. Así, sabemos que en 1526 esta junta denunció el fracaso de la conversión de los moriscos porque no se había materializado una aculturación religiosa e ideológica que terminara con el sentir islámico de esta población. A pesar de ello, Carlos V concedió un aplazamiento de estas medidas a cambio de un nuevo impuesto ${ }^{25}$

Ante la amenaza proveniente del Mediterráneo que acechaba con incursiones en el territorio espańol por parte del Imperio Otomano, como de la piratería berberisca, se acordó cambiar la política de persuasión que hasta entonces se había llevado a cabo con respecto a la comunidad morisca, ejerciendo un control de medidas más represivas. Posteriormente, vuelve a plasmarse este criterio en el sínodo provincial de los obispos del reino de Granada en 1565, por iniciativa del arzobispo de Granada Pedro Guerrero. Felipe II, ante el temor de que se hablase de una guerra en el propio corazón de la monarquía, dio finalmente su aprobación y el resultado fue la pragmática de 1 de enero de 1567 .

Aún los sones de guerra estaban silenciados para la villa de Zalamea el año de 1568 . Si bien, los espías tanto de un bando como del otro, advertían de que el conflicto podía estallar de inmediato. Por aquellos años, la localidad de Zalamea la Real, conocida como Zalamea del Arzobispo, era un territorio seńorial perteneciente al Arzobispado de

23 J. Caro Baroja, Los moriscos del Reino de Granada. Ensayo de historia Social, Madrid, 2000, pp.40-42.

24 A. Domínguez Ortiz, B. Vincent, Historia de los moriscos. Vida y tragedia de una minoria, Madrid, 1978, p. $20-22$.

25 Ibidem, p. 20-22. 
Sevilla. Sabemos que el 13 de diciembre de ese mismo ańo, congregado el cabildo de la Catedral presidido por don Cristóbal de Padilla, canónigo de la Santa Iglesia sevillana por fallecimiento de don Hernando de Valdés, nombraron oficiales para cubrir los cargos disponibles que se habían producido durante la sede vacante. Éstos nombraron por alcalde mayor de la villa de Zalamea al canónigo Luis de Lezana y le dieron poder para ejercer dicho oficio ${ }^{26}$.

La rebelión se inició la víspera de Navidad de 1568. Una de las matanzas más grandes tuvo lugar el 28 de diciembre, día de los Santos Inocentes, donde murieron un gran número de curas y frailes, quemándose iglesias y altares. Felipe II quedó horrorizado. Esta primera fase, que duró hasta marzo de 1569, fue conducida por el marqués de Mondéjar y el marqués de los Vélez, campańa que se estancó entre otras razones debido a la enemistad entre ambos y la forma de cómo afrontar la guerra. Finalmente, fracasó y esta rebelión cobró nueva fuerza a causa de los excesos cometidos por los soldados y del lado morisco por las muertes de curas y sacristanes, la destrucción de iglesias, las profanaciones y otros actos de venganza contra los cristianos viejos. ${ }^{27}$

Nuevamente, volvió a reunirse el cabildo en sede vacante ${ }^{28}$ el sábado día 8 de enero de 1569, presidido por el señor Cristóbal Padilla, deán y canónigo de esta iglesia, siendo llamado a testimoniar Antonio Díaz para responder a una carta firmada por el rey Felipe II, en la cual comunica que en algunos lugares, como Órgiva, se ha levantado un número de gente en el campo con banderas y sin contar con la mesnada proveniente del mar y en vista de la situación, había informado al Marqués de Mondéjar, capitán general del regimiento de Granada. Esta misiva fue firmada con sello real a primeros de enero de 1569.

En ese mismo mes de enero, Luis de Lezana se desplazó a Zalamea para realizar un padrón de los vecinos y moradores de la villa y sus aldeas, donde se relacionaban los hombres aptos para ir a la guerra, junto con las armas que tenían así como las que debían comprar, dándoles para ello un plazo de ocho días, bajo pena de dos mil maravedís a cada uno que no cumpliera la orden. Con tal fin, mandó a Diego Martín para que en la plaza del pueblo y ante la puerta de la audiencia y casas del Cabildo pregonara la obligación de todos los vecinos de presentar las armas que tuvieran y en la plaza hacer demostración de ellas, con expreso mandato de no deshacerse de las mismas hasta que otra cosa fuese mandada. La lista fue firmada por Luis de Lezana el 16 de enero de 1569, siendo testigo el señor licenciado Rodrigo Alonso, clérigo de Zalamea, así como los escribanos públicos de la villa ${ }^{29}$.

En el padrón se recogen todos los hombres aptos para ir a la guerra de la villa de Zalamea y de sus 27 aldeas.

26 Sevilla, ACS, caja $11089 \mathrm{n}^{\circ} 2$

27 A. Domínguez Ortiz, B. Vincent, Historia de los moriscos, Vida y tragedia de una minoría, Madrid, 1978.

28 Sede vacante es el período y las circunstancias especiales que se dan cuando una diócesis o iglesia particular queda sin obispo o pastor.

29 ACS, caja 11089 no 2 


\begin{tabular}{|l|l|}
\hline Zalamea & 125 hombres \\
\hline La Sierra & 6 hombres \\
\hline Casillas & 6 hombres \\
\hline Puerto & 4 hombres \\
\hline Fuente Limosa & 6 hombres \\
\hline El Villar & 54 hombres \\
\hline Posadas & 14 hombres \\
\hline Naranjo & 5 hombres \\
\hline Encinosa & 3 hombres \\
\hline Toril & 6 hombres \\
\hline Buitrón & 18 hombres \\
\hline Buitroncillo & 5 hombres \\
\hline Pozuelo & 15 hombres \\
\hline Rubios & 4 hombres \\
\hline Membrillo & 13 hombres \\
\hline Cabeza de la Varas & 7 hombres \\
\hline Marigenta & 16 hombres \\
\hline Majanillos & 4 hombres \\
\hline Delgadas & 9 hombres \\
\hline Villar & 7 hombres \\
\hline Monte de Alonso Romero & 3 hombres \\
\hline Molinos & 5 hombres \\
\hline Canos & 7 hombres \\
\hline Duçeta & 2 hombres \\
\hline Ventoso & 21 hombres \\
\hline Riotinto & 8 hombres \\
\hline Ermitaños & 6 hombres \\
\hline Campillo & 6 hombres \\
\hline
\end{tabular}

Hombres aptos para la guerra de la villa de Zalamea y sus aldeas.

De un total aproximado de 385 hombres aptos para la guerra, 125 vivían en el pueblo y el resto en las diferentes aldeas; en el padrón se incluyen los que estaban ausentes o padecían algún tipo de discapacidad. Aun considerando esto último, aproximadamente sabemos que, de cada 100 hombres, 32 residían en el pueblo y 68 en las diferentes aldeas. Fueron mayoritariamente estos aldeanos, no sólo aquí, sino en gran parte del territorio español, los que impulsaron y mantuvieron el gran Imperio español durante casi siglo y 
medio enrolados en los tercios concejiles o de Flandes. Sangre de aldea, sangre de pobres, siempre los más expuestos a los designios de la patria, siempre los menos favorecidos.

Ésta es la relación de los hombres para la guerra de la aldea de Marigenta y su armamento. En ella también se recogía la edad de la persona y los hijos que tenían.

\begin{tabular}{|l|l|l|}
\cline { 2 - 3 } \multicolumn{1}{c|}{} & Armas que posee & Armas que debe comprar \\
\hline Juan Rodríguez & Espada & Ballesta \\
\hline Hernando García & Arcabuz & \\
\hline Juan García & Ballesta, lanza & \\
\hline Juan Esteban & Dardo & Ballesta, espada \\
\hline Alonso Rodríguez & Dardo & Arcabuz \\
\hline Lorenzo Domínguez & Lanza & Espada \\
\hline Pedro Juan & Ballesta & Espada \\
\hline Alonso Bernal & & Dardo \\
\hline Juan Pedro Gil & & Lanza, espada \\
\hline Martín Esteban & Dardo, espada & \\
\hline Hernando Lorenzo & Espada & Ballesta \\
\hline Martín Delgado & Espada & Lanza \\
\hline Pedro Rodríguez & Lanza & \\
\hline Alonso Mamé & Espada & Arcabuz \\
\hline Francisco Romero & Espada & Ballesta \\
\hline
\end{tabular}

Relación de los hombres para la guerra de la aldea de Marigenta y su armamento.

Un mes después, el 16 de febrero de 1569, el Rey Felipe II dirige una carta al cabildo en sede vacante para que desista de enviar "la Gente de Guerra" que había pedido el conde de Tendilla para el reino de Granada. ${ }^{30}$

En los primeros momentos de este conflicto los soldados alistados eran tropas concejiles, una fuerza de combate y defensa conformada por los habitantes de un lugar, que, convocadas y controladas por el concejo del lugar o del noble que ostentaba el señorío, debían obediencia al rey. No eran tropas profesionales, no tenían preparación militar, ni preparación psicológica; muchos soldados para salir de la pobreza llegaban a esta realidad cruenta, movidos por el saqueo y por el botín de guerra. Esta situación forzó a una parte de los moriscos a una rebelión que en gran medida no deseaban y a su vez, afirmó la insu- 
rrección de los moriscos más beligerantes. En la primavera de 1569, lo que se preveía que iba a ser un conflicto localizado se recrudece como un conflicto de mayores proporciones.

Conocida la noticia del levantamiento morisco, se realizó un escrito de apercibimiento por parte de Felipe II a los cabildos para el alistamiento de las tropas en los territorios próximos de Andalucía y Murcia. Posteriormente, se extendió a otros lugares como Extremadura, la Mancha, etc.

La tarea de reclutamiento no fue fácil por la división interna entre los distintos cabildos y entre los propios dirigentes; las razones eran obvias, el aprovisionamiento y equipamiento de las tropas y el dinero que tenían que haber recibido. De los 2000 hombres que el conde de Tendilla solicitaba, sólo se pudo conseguir la mitad de los soldados requeridos. El resto de tropa llegaría cuando el conflicto se recrudeció.

Ante la inoperancia de los tercios concejiles, Felipe II decide mandar a su hermanastro don Juan de Austria. En esos momentos, el líder moderado del bando morisco, Aben Humeya, fue asesinado y le sucede al mando su primo y adversario Aben Aboo, con una visión más radical del conflicto. Don Juan de Austria mandó un ejército de soldados profesionales. Con la caída de la población de Galera en 1570 y salvo pequeñas escaramuzas, esta rebelión concluyó a principios de 1571, y se puede decir que oficialmente con el asesinato de Aben Aboo el 13 de marzo.

En el reino de Sevilla la soldadesca la formaban, por lo general, los más pobres. Pero si difícil era la realidad, más dura se volvía en el frente de combate. La falta de un armamento adecuado a las condiciones de la guerra, sin provisiones suficientes y el retraso o la falta de sueldo, dejaban al soldado en una situación límite, en un territorio de difícil orografía, ideal para las emboscadas moriscas, sin olvidar el crudo invierno de aquel año de 1569. Todo esto llevaba al extremo la tragedia de sus vidas. El único motivo para no desertar radicaba en el miedo al castigo, que no era otro que la horca o el herrado en la cara para dar nombre a su cobardía, como también el pillaje indiscriminado practicado por estas milicias concejiles, integradas por civiles con escasa preparación militar y sin un sueldo regular.

Estos soldados que provenían mayoritariamente del medio agrario, impulsaron y sostuvieron durante casi un siglo y medio el periodo histórico más brillante del pueblo español, con sus luces y con sus sombras. Tercios concejiles o Tercios regulares, en su mayoría hombres del medio rural, sangre de pueblo, sangre aldeana empujados por la miseria y el hambre o por la ambición de fortuna y gloria, o por ambas a la vez. Ellos fueron en realidad quienes sostuvieron la hacienda de los monarcas y el Gran Imperio Español. 
